\title{
Behaviour of high alumina cement concrete under sustained loading
}

\author{
R. N. SWAMY \& R. L. ANAND
}

\section{Mr I. W. Menzies, F}

Unfortunately, in terms of the normal life span of a building, a period of one year cannot be counted as long term, and so to regard the Authors' results as anything other than short term would be unwise. The use of Alag as part of the fine aggregate introduces a material-seldom found in existing structures-whose long-term behaviour is itself unknown and which casts doubt on the applicability of the results to existing high alumina cement beams.

52. Despite the high water cement ratio used, the loss of strength reported in the Paper is much less than that found in practice, where losses in excess of $70 \%$ are not uncommon. It could perhaps be inferred that accelerated conversion is less harmful than that under more normal ambient conditions, but the sample is too small to justify such an assumption as being of general application. No figures are given for the degree of conversion which occurred in the beams or in the prisms and further deterioration cannot be excluded. In view of the different storage conditions it is probable that the rates of conversion in the two types of specimen were also different. It is indeed possible that little conversion has taken place in the beams.

53. The conclusion in $\S 35$, that the change in the rate of creep in the prisms at about 200 days is due to conversion, is unsubstantiated. No evidence is adduced to establish that conversion reached a critical value at such an age. It appears that this phenomenon was observed only in the prisms. If it is due to conversion and conversion is occurring in the beams but has not yet reached this critical value, when this occurs one would expect a rapid increase in the rate of strain in the beams. Was this allowed for in the calculated ultimate deflexions?

54. As there has been little structural use of high alumina cement in reinforced members, interest must centre on the results given for the prestressed beams. From the data given it is difficult to ascertain the stresses in beams L7 and L8 at the time of loading. If the maximum stress at transfer were $34.6 \mathrm{~N} / \mathrm{mm}^{2}$ the actual stress immediately before application of the load would be less than that. The applied moment (Table 3 ) would then appear to result in an approximately triangular stress distribution with a maximum value of about $28.0 \mathrm{~N} / \mathrm{mm}^{2}$ and a minimum less than $4.2 \mathrm{~N} / \mathrm{mm}^{2}$. With such a large difference in stress between the outermost fibres it is surprising that the rate of creep found by the Authors is of the same order on both faces (Fig. 7) and that the creep in the least stressed fibre is tensile. If, as a result of losses before the application of the load, the bottom fibre is in tension under applied load plus prestress, the value of such a stress must be very low. Tensile strains of the

Paper published: Proc. Instn Civ. Engrs, Part 2, 1974, 57, Dec., 651-671. 
magnitude shown would imply a creep coefficient in tension much greater than that in compression. Can the Authors explain this anomaly?

55. The assumption in $\$ 25$ that compression steel is likely to be present in practice is not borne out by the facts. A high proportion of the high alumina cement which has been used in the UK has been in relatively small section standard units where compression reinforcement is rarely found.

56. A comparison of the behaviour of the beams shown in Fig. 5 would have been simpler had the same origin and vertical scale been used for all beams or if both prestressed and both reinforced beams had been plotted on the same basis.

57. The duration of the tests and the number of specimens tested are inadequate to establish that the long-term deformations of high alumina cement beams need not cause alarm. Unless it can be shown that the beams tested have reached or passed their minimum strength and cannot undergo further deterioration, it would be unwise to assume that they will continue to behave in an acceptable manner. Even if it were to be established that deformation is not a problem there remain many aspects of the long-term behaviour of high alumina cement which require investigation, e.g. shear strength, bond strength, porosity, corrosion of embedded steel and resistance to chemical attack.

58. Any contribution to the knowledge of the behaviour of high alumina cement is to be welcomed, but with events in Stepney, Camden and Leicester and in other countries in mind, the knowledge that its use is either banned or severely restricted in many countries and that an amendment to the Building Regulations excludes it from the 'deemed to satisfy' provisions, it is unlikely to be used structurally in the foreseeable future. However, because of the number of existing buildings in which it has been used, every effort must be made to discover reliable methods of ascertaining the present safety and forecasting the future behaviour of existing structures. Such efforts must recognize that generally there is no way of ascertaining with certainty the manufacturing conditions, the original water-cement ratio, the mix proportions, the ambient conditions throughout the life of the member, the present strength (other than on a small number of samples which usually show a wide scatter of results) or the present percentage conversion (other than on the same basis and with the same shortcomings as for strength).

59. The dangers of basing prognostication on inadequate knowledge of a problem as complex as the behaviour of high alumina cement are illustrated by the comment of Martin, Rauen and Schiessl in the 1973 Quinquennial Report of the Munich Technical University: "Although it appeared until recently that the difficulties arising from the widespread use of hac in prestressed concrete were a matter of the past . . . it must now be admitted that today more questions remain to be solved than ever before.'

\section{Mr A. S. Safier, Charles Weiss and Partners}

The Paper deals with a subject on which many engineers are anxious to extend their knowledge. Unfortunately it gives little information on two of the most critical parameters--the rate of conversion of the concrete of the test beams and the time and environment of the initial curing-affecting the long-term behaviour of high alumina cement concrete. It also omits other details such as a diagram of the reinforcement of the test beams.

61. The synopsis and introduction to the Paper leave one with the impression that the tests were designed with beams of normal production in mind and are relevant to the Camden, Leicester and Stepney collapses. However, this is not so; the tests were obviously started long before the Camden incident and the specimens are not typical of high alumina cement concrete production as normally encountered in prestressed precast beams.

62. Alag aggregate $(\S 7)$ is not in common use, nor are environmental conditions in buildings where high alumina cement concrete is normally encountered $15.7 \pm 0.5^{\circ} \mathrm{C}$ and $50 \pm 2 \%$ relative humidity $(\S 9)-20^{\circ} \mathrm{C}$ at $75 \%$ relative humidity would be more 
accurate. It is difficult to understand why the aggregate particulars are given in detail.

63. With reference to $\S 2$, high alumina cement concrete converts and loses strength in normal environmental conditions as well as in 'warm, humid conditions'. Conversion ( $\$ 4)$, however slow, is always accompanied by a strength reduction because of the porosity which is an essential feature of the crystalline changes of conversion. The use of granite aggregate in high alumina cement concrete $(\$ 5)$ is to be discouraged.

64. The creep curves shown in Fig. 3 terminate at about 650 days with no indication that the limit of creep has been reached. Every practising engineer should be very worried if creep were to continue at the rates indicated.

65. In the column in Table 3 showing age at testing how were the 15 and 19 days determined? Why did the Authors not choose 1, 7 or 28 days as is common in concrete testing so as to permit comparison with other publications and Fig. 3 ? With reference to $\S 14$, stirrups are not commonly used in mass produced high alumina cement concrete prestressed precast beams.

66. In production beams the prestress is more often than not transferred at 24 hours and not three days. This would have affected the rate of creep ( $\S 13)$. Fig. 3 shows a major increase in creep at the age of 250 days. Why is this not reflected in the deflexion diagram (Fig. 5)?

67. The deflexion prediction methods described in $\$ 24$ are for ordinary Portland cement concrete but because of the variability of this they should not be used in predicting deflexions of high alumina cement concrete.

68. With reference to the last sentence of $\S 25$, compression steel is not used in practice in prestressed precast beams and the reduction of deflexions by providing compression steel equal to the tension steel is uneconomic. These suggestions, taken out of context from reference 18 , emphasize the purely theoretical nature of the Paper.

69. Cracks in prestressed beams $(\S 33)$ are not acceptable and with the lack of the protection of the alkalinity of ordinary Portland cement concrete would soon lead to steel corrosion in prestressed high alumina cement concrete beams. The same, although in the longer term, is true of reinforced high alumina cement concrete beams.

70. With reference to $\$ \S 38$ and 44 , Fig. 3 shows that the creep curve had not flattened out. It could be misleading if one were to draw comparative conclusions from the information obtained so far. Why did the Authors not make and test in parallel ordinary Portland cement control beams with the same mix proportions and aggregate?

71. The span-deflexion ratios reported in $\S 45$ are, in practice, unacceptable. Tests of beams for 650 days can hardly be described as long-term.

\section{Mr J. H. Bungey, University of Liverpool}

It is reassuring to have evidence that serviceability criteria are unlikely to be critical for high strength, high alumina cement concrete, but it is also important to appreciate that the mix used is not likely to be representative of the bulk of high alumina concrete which has been used in the UK. Despite the relatively high water/cement ratio, it would appear from Fig. 2 that the residual strength after conversion is unlikely to have fallen below $60 \mathrm{~N} / \mathrm{mm}^{2}$ in the specimens subjected to creep and sustained loading tests. Indeed the strength in the high alumina cement beam specimens is probably at a considerably higher value because of the less severe curing conditions described.

73. High alumina concrete has generally been made with gravel aggregates, and on the basis of many recent investigations in the Merseyside area it would appear that residual compressive strengths of $30 \mathrm{~N} / \mathrm{mm}^{2}$ are not uncommon. It has generally been found that such cases do not, as yet, suffer from serviceability damage although a number of cases where average concrete strengths are around $20 \mathrm{~N} / \mathrm{mm}^{2}$ have 


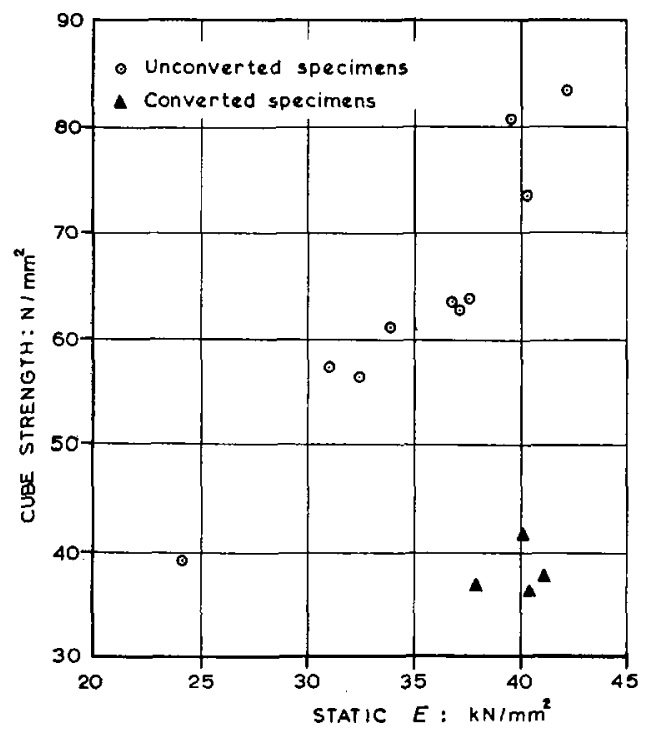

Fig. 9. Relationship of compressive strength and static modulus of elasticity for high alumina concrete with $20 \mathrm{~mm}$ gravel aggregate

shown excessive deflexions. In many instances it is found that the strength of the highly converted concrete, although much reduced from the 24 hour value, is still adequate from considerations of member ultimate strength. However, the long-term serviceability prospects for such members which are still at a relatively early stage of their life must be uncertain.

74. The effect of curing conditions on compressive strength is shown in Fig. 2 and the variation of creep strains with time for converting concrete in Fig. 3 . The conclusion that the sudden increase in the rate of creep at about 200 days is related to the conversion process raises the point that there appears to be a time lag of about 100 days between the start of the strength decrease and the start of creep increase. In considering this phenomenon it is interesting that loss of strength due to laboratory accelerated conversion is not always immediately accompanied by a corresponding change in modulus of elasticity.

75. Figure 9 shows results obtained for static moduli determined in accordance with BS 1881 on $500 \times 100 \times 100$ prisms of high alumina concretes compared with corresponding $100 \mathrm{~mm}$ cube strengths. The mixes were of varying proportions based on natural sand and $20 \mathrm{~mm}$ gravel aggregates as commonly used for structural applications of this material. The unconverted specimens were tested approximately 24 hours after air curing and the cluster of results around $60 \mathrm{~N} / \mathrm{mm}^{2}$ corresponds to gap-graded mixes designed to give $50 \mathrm{~N} / \mathrm{mm}^{2}$ minimum at 24 hours. A separate group of four specimens of this normal concrete, when subjected to water curing at approximately $50^{\circ} \mathrm{C}$ for five days followed by one day in air at about $18^{\circ} \mathrm{C}$, gave the results labelled converted specimens. It is apparent that despite a reduction in strength of about $40 \%$ the static modulus of elasticity is not reduced. Corresponding tests for dynamic modulus of elasticity both by the BS 1881 method and by ultrasonic techniques followed a similar pattern. These specimens still show no signs of 
reduction in elastic modulus after one year, whether stored dry in the laboratory or moist at $20^{\circ} \mathrm{C}$ in a curing room.

76. Tests currently in progress on similar mixes subjected to a variety of curing conditions indicate that this feature does not always occur and that in some instances reductions in elastic modulus corresponding to the strength reductions do occur.

77. It has been well established by various methods that the modulus of elasticity of converted concrete in the field can be reduced by conversion. ${ }^{22,23}$ It is interesting therefore to consider the implications of these variations in behaviour, and the possibility of a time lag between elastic modulus and compressive strength and consequent effects on the results of relatively short-term laboratory investigations.

78. I would welcome the Authors' views on these features, and their comments on the probable long-term behaviour under sustained load of concrete made with gravel aggregates and with strengths considerably below those obtained in their experiments.

\section{Dr Swamy and Dr Anand}

While searching for data in connexion with the effects of conversion on the behaviour of high alumina cement concrete beams in service, it became clear that there were few available. The programme of research, part of which is reported in the Paper was therefore undertaken to study the behaviour of converting high alumina cement concrete.

80. It is now well established that the effects of conversion cannot be prevented, and that although the rate of conversion depends on the ambient temperature and humidity, probably the most important factor that determines the extent of reduction in strength and the consequent resistance of high alumina cement concrete to deformation and chemical attack is its porosity, i.e. the amount of total water-cement ratio used in the concrete. In the tests reported, therefore, a moderately high watercement ratio was used to establish its influence.

81. Long-term tests, although desirable and useful, are time consuming and are necessarily of limited duration, and very long-term tests are rare. 17, 21,24 However, it is doubtful if data extending over the normal life-span of a building are necessary, as suggested by Mr Menzies, to make reasonable and valid predictions of timedependent deformations of concrete structures.

82. The long-term deformation of concrete structures is determined primarily by shrinkage and creep, both of which influence cracking and deflexion. With most types of concrete and normal sized structural members, most of the deformation due to shrinkage and creep would occur within the first year of service. $11,15,17,25,28$

83. For normal concrete structures therefore test data for $2-3$ years ${ }^{21.24}$ should generally be adequate to give a fair indication of the long-term deformations that are likely to occur, although deformations due to shrinkage and creep can continue for several years. With high alumina cement concrete there is the further effect of conversion on the strength and deformation of the members to be considered. If design is based on the minimum converted strength, the anticipated behaviour of such beams should be no different from that of other concrete members of similar strength; however, if design is based on the unconverted one day strength, then test data should extend until conversion is completed. Once conversion is complete no changes take place either in the strength or deformation of the member due to chemical reactions of the cement.

84. The results on shrinkage and creep presented extend over 21 months. The conversion process of specimens subjected to the same curing regime occurred over about 4-28 months, although by about 21 months most of the conversion had occurred and only negligible reduction in strength took place between 21 and 28 months. The data presented in Fig. 3 and Table 2 may therefore be considered to reflect the overall effect of conversion on shrinkage and creep.

85. Although Alag has been used in the tests reported as partial replacement of natural fines, there is no reason why these results should not be applicable to beams 


\section{DISCUSSION}

without Alag aggregate. The use of Alag results in a strong aggregate-matrix bond because of its chemical affinity to high alumina cement; and because Alag has the same order of alumina content as high alumina cement, it may be considered as part of cement so far as its effect on the behaviour of the beams is concerned.

86. No figures for the degree or rate of conversion were reported in the Paper because only few differential thermal analysis (DTA) tests were carried out. However, additional tests are being carried out. Ultrasonic pulse velocities have been taken at regular intervals and it is intended to correlate the two.

87. The degree of conversion per se is less important in design because the aim is to design for the fully converted state. There is thus no need for data on structural deformation for different degrees of conversion. The extent of conversion was monitored mainly by its influence on compressive strength (Fig. 2 ) and conversion is assumed to have ceased when the minimum strength is reached. DTA tests were used only as spot checks initially. Subsequent appraisal tests have shown the inherent limitations of DTA tests, and precise values of the rate or degree of conversion have to be viewed with reserve, although they provide useful guidance. From a structural behaviour point of view, it is more appropriate to rely on the minimum strength as a measure of full conversion. The rate of conversion is dependent on varying service conditions, and so the most useful data for design are obtained when full conversion has occurred.

88. So far the beams have not shown any abrupt increase in the rate of strain or deflexion that could be attributed to conversion. Pulse velocities show that less than about $30 \%$ conversion has occurred, and the data show only a gradual increase in deformation. This explains why the change of slope in the creep curves shown in Fig. 3 is not reflected in the deflexion diagrams of Fig. 5.

89. Mr Menzies has queried the conclusion in $\$ 35$. The creep and shrinkage specimens were cured under the same conditions as the cube specimens $A$ in Fig. 2. Fig. 2 shows that the curing conditions used to accelerate conversion caused it to take place over 4-28 months. The effect on creep does not begin until about 200 days (Fig. 3) and the subsequent change of slope in the creep curve is a clear reflexion of the effect of conversion on creep. Conversion, except at high temperatures, takes place over a period of time, as does the resulting change in creep deformation (Fig. 3 ).

90. Mr Safier is correct in that the creep curves shown in Fig. 3 indicate no limit and should cause concern if they were to continue at the rates shown. However, a comparison of Figs 2 and 3 shows that at 650 days the corresponding cube strength has almost reached a minimum and most of the conversion has taken place. It is therefore logical to conclude that the creep strains are unlikely to continue at the rates shown. This is confirmed by the creep data which show that the strains reach a limiting value at $850-900$ days. It seems that the strains at 650 days represent about $80 \%$ of the limiting creep, but the data need to be monitored further before positive conclusions can be drawn.

91. The large creep strains shown in Fig. 3 should not be interpreted too literally. In structural terms, it is the specific creep or creep per unit stress that is more significant than the absolute magnitude of creep strain, and the effect of conversion on this is discussed in $\S 13$. The stress-strength ratios based on the converted strength are much higher than those normally used in design (\$11). A more realistic evaluation of ultimate creep strains is shown in Table 5. These are based on the deformations which occur when conversion is gradual under internal environmental conditions.

92. Mr Menzies queried the tensile strain distribution in Fig. 7(b). Beams L7 and L8 were loaded as described in $\S 15$. However, in beam L7 the applied load was momentarily increased to cause cracking in the tension zone. Beam L7 was therefore subjected to a sustained load in a cracked state to examine the effects of conversion on cracking and the associated deflexion (Table 6). The tensile strains shown in Fig. 7(b) are thus those measured over the cracked region and are likely to include 

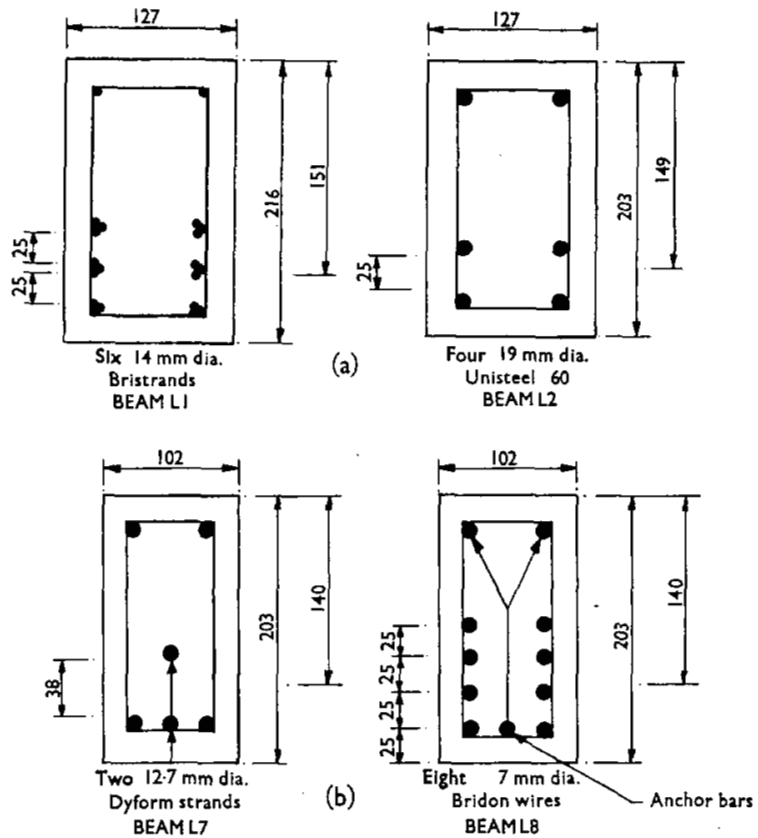

All dimensions in mm

Fig. 10. Details of test beams ; (a) reinforced beams, (b) prestressed beams

some crack width. They should not therefore be interpreted too literally in terms of creep strains.

93. Although high alumina cement has not been used extensively in reinforced concrete in the UK, it has been elsewhere. One aim of our tests was to explore the possibility of using high yield steel with a characteristic strength of $700 \mathrm{~N} / \mathrm{mm}^{2}$ because the use of normal high yield steel cannot take full advantage of the high concrete strengths obtainable from high alumina cement concrete.

94. Details of the initial curing of the beams and prisms are given in $\$ \S 9$ and 14 and Fig. 2. The location of the reinforcement is shown in Fig. 10.

95. The beams were subjected to normal curing and environmental conditions. Fig. 2 shows that little or no reduction in compressive strength has occurred so far while the beams were under load, although about $30 \%$ conversion had occurred (\$8 86-88).

96. The temperature and humidity conditions adopted for the creep and shrinkage tests are not unusual. The effect of temperature on creep is generally less important, and there is little or no effect on creep for temperature changes of 15-20 deg C. The temperature of $20^{\circ} \mathrm{C}$ is applicable only to internal environments remote from artificial light and sunlight which can raise temperatures to $30-35^{\circ} \mathrm{C}$. Creep becomes important only if the concrete is allowed to dry under the effect of temperature.

97. Similar arguments would apply to the suggestion of $75 \%$ for relative humidity. In a centrally heated internal environment, the relative humidity could be as low as $50 \%$, whereas in other exposed situations it could be $85 \%$. It is more appropriate to carry out shrinkage and creep tests at certain standard conditions and apply suitable 
correction factors for other environments in accordance with the CEB-FIP recommendations. ${ }^{27}$

98. It would seem to be simple to calculate the weights of material.

99. Mr Safier says that the use of granite is to be discouraged. The aggregates to be excluded from use with high alumina cement are those which contain free or releaseable alkalis which in the presence of water and atmospheric carbon dioxide react to form alkali carbonates which then attack the calcium aluminate hydrates. This phenomenon known as alkaline hydrolysis ${ }^{28}$ is a chain reaction and destroys porous high alumina cement concrete. Alkalis accelerate the set and initial strength development of high alumina cement and the rate of conversion. High alumina cement concrete is also sensitive to excess fine dust in aggregates which liberate alkalis.

100. In our tests, a crushed granite had no adverse effects in relation to the rate of conversion or any other property. The quality of aggregates varies widely and, if adequate precautions are taken, even supposedly inferior quality aggregates can be used satisfactorily with a well compacted impermeable concrete.

101. Mr Safier questions our statement about conversion and yet makes the oftrepeated versions of conversion which are too general. The chemistry of high alumina cement concrete as known is well documented and we only briefly touched on it.

102. The inference made by Mr Menzies that accelerated conversion is less harmful than that under normal ambient conditions is not justified by our results or other available data. The prevalent idea that accelerated conversion is more harmful is not justified either to date. However, there is evidence that the loss in strength is less when conversion proceeds over several years.

103. Although the influence of temperature and water content are interdependent, the water-cement ratio is the more important parameter that determines the changes in heat of hydration, the final converted strength, durability and impermeability of high alumina cement concrete. Above $w / c$ ratios of $0.35-0.40$, porosity increases rapidly irrespective of the type of cement; with high alumina cement, conversion produces an increase in the total volume of pores and in the size of the pores. ${ }^{29}$ The influence of the combination of conversion and high $w / c$ ratios on the properties of the converted concrete can therefore be easily realized.

104. There is no direct relation betwen loss in strength and degree of conversion, and from a design point of view there is no need to correlate structural deformation with the degree of conversion. It is more important to establish the effect of the converted reserve strength on the strength and durability of high alumina cement concrete.

105. The one-day strength of unconverted concrete is not an adequate basis for design. The general form of the relation between the strength of fully converted concrete and the one-day strength of unconverted concrete at various $w / c$ ratios shows that the rate of loss in strength is different in the two cases.

106. Many data emphasize the interdependence of $w / c$ and the temperature of storage on their influence on conversion. Even when high alumina cement concrete, at a given $w / c$ ratio, has been stored in water under different environmental conditions, the loss in strength observed with time can be explained only by the higher average temperature of storage. Tests on the strength of specimens extracted from thirty year old piles confirm this. ${ }^{30}$

107. Mr Safier queried the age of testing of the beams. The stress-strength ratio is the important parameter and so the beams were loaded at a convenient time after this ratio remains fairly constant.

108. Mr Safier says that neither stirrups nor compression reinforcement are commonly used in mass produced high alumina cement prestressed precast beams. If secondary reinforcement is necessary from the point of view of design, then these must be provided whether the members are produced in situ or precast. Closely 
spaced beams carrying floor loading, purlins and so on are unlikely to need stirrups or compression reinforcement from strength considerations, but these form only one field of application of precast members.

109. Design should also consider serviceability conditions from long-term deformation. We would have thought that positioning reinforcement to control cracking and/or deflexion was the essence of design. One serviceability failure frequently encountered is the lack of consideration or inaccurate assessment of this. It is important to assimilate the results of research in design. Economics are not related to cost of materials alone; perhaps serviceability should be a more important criterion.

110. In precasting transfer of prestress occurs before three days, and often before 24 hours. This would affect the rate of creep (Fig. 3). However, this differential rate of creep occurs only in the early part of the loaded life of the member, and these differences disappear with time (\$13). It is not age per se that determines creep deformation, but the stress-strength ratio at the time of loading. ${ }^{31}$

111. In long-term deformation, the influence of shrinkage and creep predominate, and if the appropriate coefficients are used in equation (3) the basic deflexion prediction methods should apply equally to ordinary Portland cement and high alumina cement concretes. In our tests the beams, converting under normal environment, show no abnormal effects due to conversion; the ultimate deflexions in Table 4 are therefore based on the creep deformations occurring in the beams themselves. However, should the effects of conversion subsequently show abnormal rates of creep, this could be catered for in the predicted values by the appropriate creep factors from Fig. 3.

112. Mr Safier's contention that cracking in high alumina cement concrete beams would soon lead to steel corrosion is not borne out in practice. Although high alumina cement is less alkaline than ordinary Portland cement, it is sufficiently alkaline to protect steel. The $\mathrm{pH}$ value of high alumina cement is about 11.5 ; it rises to about 12-12.5 during hydration, but that of converted concrete remains at about $11 \cdot 5 .{ }^{32}$ Porosity and cracking can accelerate carbonation and carbonated concrete is less alkaline. This applies equally to both types of concrete but with high alumina cement concrete conversion leads to increased porosity, and there is therefore the need to avoid high $w / c$ ratios. However, for several beams tested in the current appraisal there was no case of steel corrosion in high alumina cement concrete even when inadequate cover was used and there is no reason why corrosion should be a problem any more with high alumina cement concrete than it is with any other concrete, at least as far as the UK is concerned.

113. Table 7 and reference 15 show that we made tests for creep and sustained loading on Portland cement concrete of strength comparable with that of high alumina cement.

114. The span-deflexion ratios shown in Table 4 are unacceptable, but these values relate to high concrete stresses, and steel stresses of $346 \mathrm{~N} / \mathrm{mm}^{2}$ in the case of beam L1. Table 7 shows that even when normal stresses are used in the concrete and steel, the resulting span-deflexion ratios are unacceptable in several cases according to CP $110 .{ }^{12}$

115. A continuous sustained loading test is a severe loading condition not often obtained in practice. The predominant causes of long-term deflexion are shrinkage, creep and cracking, and Table 7 emphasizes the need for the proper assessment and control of such deformation. Thus published research can be an invaluable asset to design.

116. Mr Bungey is correct in that there is a time lag of about 100 days between the start of the strength decrease and the start of the creep increase. The effects of conversion are thus not immediately apparent on the behaviour of the concrete. Both conversion and creep are time-dependent, and at the rate at which conversion occurred in the prisms it took 2-3 months from the start of conversion for there to be 


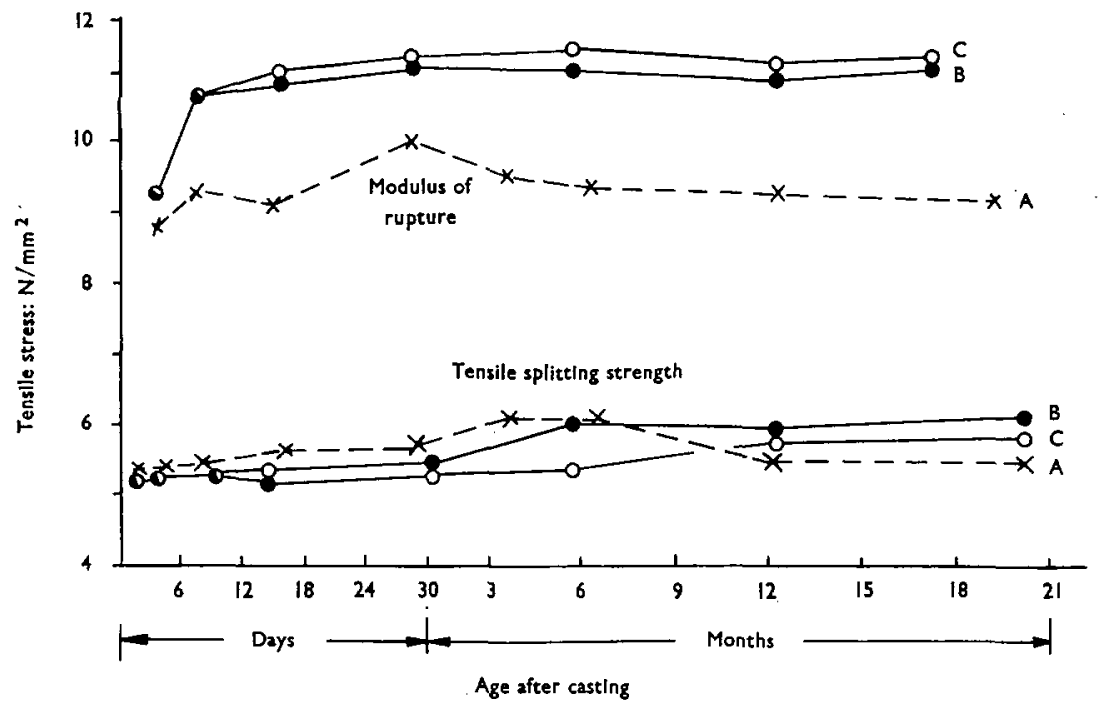

A: cured at $27 \pm 3^{\circ} \mathrm{C}, 95 \pm 5 \%$ relative humidity for 3 days followed by constant temperature and humidity ( $15 . \overline{7} \pm 0.5^{\circ} \mathrm{C}, 50 \%$ relative humidity)

B: water cured at $1 \overline{8}^{\circ} \mathrm{C}$ after demoulding

C: cured under natural atmospheric conditions after demoulding

Fig. 11. Variation of modulus of rupture and tensile splitting strength for various curing regimes

sufficient reduction in strength for it to be reflected in the creep deformation changes. The time lag is likely to be less for more rapid rates of conversion and greater for slow rates of conversion.

117. It can be seen from Fig. 2 that when adequate quality control is exercised, conversion due to a short exposure to warm moist conditions early in the life of a member is not immediate. Under these conditions conversion occurred over two years. Fig. 3 also shows that there is no visible evidence of the effects of conversion on shrinkage as measured usually.

118. The results in Fig. 9 confirm our results and even show a small increase in $E$ after conversion. One possible explanation for the apparently anomalous behaviour is that conversion often effects a tough outer skin, and the effects of internal porosity and the consequent reduction in strength are not always reflected in the surface measurements of strain. The unreliability of the Schmidt hammer tests, the apparent lack of change in shrinkage due to conversion, examination of fractured surfaces and experience in core drilling in the current assessment tests all appear to support this suggestion. However, it may be that there is a time lag between elastic modulus and compressive strength just as there is between creep and compressive strength. It is also possible that the variations in the observed properties with strength are a reflexion of the ill-defined relationship between strength and degree of conversion.

119. It is not surprising that the ultrasonic and dynamic tests confirmed the trend of the static modulus. Changes in pulse velocity are not sensitive enough to changes in strength, and changes in strength do not follow the same pattern as changes in resonant frequency. ${ }^{33}$ It is intriguing that reductions in elastic modulus do sometimes occur.

120. Changes in tensile strength also do not follow the pattern of changes in com- 
pressive strength due to conversion. Fig. 11 shows the variations in modulus of rupture and tensile splitting strength for three of the curing conditions shown in Fig. 2. Changes in tensile strength are much less sensitive to the effects of conversion, and it may be that it is not the same mechanism that is responsible for the changes due to conversion in the various properties of high alumina cement concrete.

121. The variations in the elastic properties of laboratory and field specimens are not peculiar to high alumina cement concrete, although they are probably accentuated. Similar variations in the properties of ordinary Portland cement concrete have also been reported. ${ }^{34.35}$

122. We see no reason to believe that the long-term behaviour under sustained load of high alumina cement concrete made with gravel aggregate should be different from that of concrete made with good quality granite aggregate except for the differences of the effect of the type of aggregate on strength and stiffness. However, no research is needed to predict the consequences of not achieving in the final structure the assumed design values of the strength of materials used and the quality control envisaged. This also depends on the actual loads on the structure compared with the design loads and other hidden factors of safety such as composite action, mobilized due to the method of construction but not envisaged in the original design.

123. Losses in strength, much higher than that reported in the Paper, have been found in practice; it may be that the mixes or the type of beams used in our tests are not likely to be representative of most of the high alumina cement concrete used in the UK. However, the beams we tested were not obtained from a manufacturer, and the differences in mixes or the provision or the lack of stirrups or other secondary reinforcement should not invalidate the general applicability of our results. If the recommendations relating to the manufacture of high alumina cement concrete beams as specified in the literature are observed in normal production, we would expect our results to be generally applicable to such beams.

124. With any material of construction, it is reasonable to expect that the assumptions made in the analysis and design in relation to the quality of the materials used and the method of production are achieved in the final state of the concrete deposited in place in the structure. No research is needed to predict the consequences of badly made concrete or if the assumptions of design strength are not achieved what the concrete is made of. A reduction or loss of any property of the material which occurs with time must be catered for in design. In prestressed concrete, allowance is made for loss of prestress. With high alumina cement concrete, the loss of strength due to conversion has been well established and it is not unreasonable to expect that the design strength should be based on the reserve strength available in the material at any given time. There is evidence to show that this has not been given adequate consideration in design.

125. There are several aspects of the behaviour of high alumina cement concrete that are not yet clear. This is just as true with ordinary Portland cement concrete; the difference is that high alumina cement is so sensitive to the environment and the $w / c$ ratio that even if the design is based on the minimum converted strength, certain precautions still need to be taken in the use of the material. ${ }^{4}$

126. We agree that it is dangerous to prognosticate on the behaviour of high alumina cement concrete on inadequate data. It is equally undesirable to be forced into panic action without a clear appraisal of the real cause of the present situation. Of the three failures in the UK, one arose because of the use of high alumina cement in an environment where it should not be used and there is enough evidence to show that design inadequacies existed in the other two failures. It is also possible that failure would have occurred in the latter two cases even with ordinary Portland cement concrete beams, although perhaps on a different time scale. Does one dare ask why high alumina cement concrete has been used so extensively if knowledge of the material is so inadequate? Or is the real lesson to be learnt that there is a need 
for the engineer to have a clearer understanding of the influence of material behaviour on structural design and, in particular, that of time-dependent deformations?

127. It is indeed necessary to pay due regard to the experience of high alumina cement concrete abroad. Failures should be viewed in the correct perspective in relation to its chemical composition, the environmental conditions of use, the forms of construction, the type of steel, the amount of water content used, quality control and so on. ${ }^{36.37}$

128. The use of high alumina cement is restricted in many countries; its structural use was banned in France in 1943 but has been permitted since 1970 under certain conditions. ${ }^{37}$ Apart from recommendations in regard to the type of aggregates and the method of manufacture, the French specifications limit the maximum $w / c$ ratio to 0.4 and the minimum cement content to $400 \mathrm{~kg} / \mathrm{m}^{3}$. In evaluating experience, it is important to aim at finding a positive solution to the engineering usage of high alumina cement.

129. In assessing current experience one must not lose sight of the number of actual failures, the number of structural elements that have been found to possess adequate factors of safety, and those requiring remedial action. ${ }^{38}$ In an extensive survey in Germany only about $0 \cdot 1 \%$ of the structures required remedial measures. ${ }^{39}$

\section{References}

22. BATE S. C. C. Report on the failure of roof beams at Sir John Cass's Foundation and Red Coat Church of England Secondary School, Stepney. Building Research Station, Garston, 1974, CP 58/74.

23. BUNGEY J. H. Ultrasonic pulse testing of high alumina cement concrete on the site. Concrete, London, 1974, 8, No. 9, Sept., 39-41.

24. Stevens R. F. Deflexions of reinforced concrete beams. Proc. Instn Civ. Engrs, Part 2, 1972, 53, Sept., 207-224.

25. Bate S. C. C. and Lewsley C. S. Environmental changes, temperature, creep and shrinkage. Proceedings of a symposium on design for movement in buildings, London, 1969. Cement and Concrete Association, London, 1969, 2/1-2/21.

26. Swamy R. N. and IbRahim A. B. Shrinkage and creep properties of high early strength structural lightweight concrete. Proc. Instn Civ. Engrs, Part 2, 1973, 55, Sept., 635-646.

27. Comite Europeen du Beton and Federation Internationale de la PreCONTRAINTE. International recommendations for the design and construction of concrete structures. Cement and Concrete Association, London, 1970, 80.

28. Robson T. D. Aluminous cement and refractory castables. In The chemistry of cements. H. F. W. Taylor (ed.). Academic Press, London, 1964, 2, 3-35.

29. Tsukayama R. Effect of conversion on properties of concrete using highaluminous cement. Proc. 5th Int. Symp. Chemistry Cem., Tokyo, 1968, III, 316-327.

30. LEA F. M. Some studies on the performance of concrete structures in sulphatebearing environments. In Performance of concrete. University of Toronto Press, 1968, 56-65.

31. Neville A. M. and Kenington H. W. Creep of aluminous concrete. Proc. 4th Int. Symp. Chemistry Cem., Washington, 1960, II, 703-708.

32. LEA F. M. The chemistry of cement and concrete, 3rd edn. Edward Arnold, London, 1970, 727.

33. Swamy R. N. and Rigby G. Dynamic properties of hardened paste, mortar and concrete. Mater. \& Struct., 1971, 4, Jan.-Feb., 13-40.

34. Elvery R. H. Problems associated with the field measurement of stresses in concrete structures. In Stresses in service. Institution of Civil Engineers, London, 1966, 43-55. 
35. Swamy R. N. and BenNetr N. P. C. Shrinkage and creep strains obtained from measurements on actual structures. In Design of concrete structures for creep, shrinkage and temperature changes, Madrid. International Association for Bridge and Structural Engineering, 1970, Preliminary Publications, Feb., 81-88.

36. BriesemanN D. Untersuchungen über die Korrosion von Spannstählen in Tertigteilen aus Tonerdeschmelzzementbeton. Betonsteinzeitung, 1969, 10, 593-603; BRE Library translation, 1974, No. 1812, Feb., 16.

37. Ggorge C. M. The structural use of high alumina cement. Lafarge Fondu International, Neuilly-sur-Seine, 1975, Apr., 15.

38. ConCrete Society. High alumina cement. Concrete Society, London, 1975, Circular, Mar., 2.

39. Evans R. H. Private communication. 